\title{
El microscopio a contraste de fases en ginecología ${ }^{(*)}$
}

\author{
Doctores Gustavo Isaza Mejía y Leonidas Rodríguez R. \\ Cátedra de Clínica Ginecológica.-Profesor Titular doctor Pedro Nel Car- \\ dona C.-Medellín, Colombia.
}

Las bases del procedimiento a contraste de fases fueron definidas por Abbe y sus colaboradores, al final del siglo pasado; pero estas primeras tentativas quedaron en el olvido. Más tarde (1934), el físico holandés F. Zernike, emprendió las primeras investigaciones principalmente desde el punto de vista óptico. Luego Kohler y Loos pudieron determinar el principio del método y sus probables dominios en la biología y en la medicina.

El progreso de la reproducción de objetos vivos con el procedimiento de Zernike, tiene la ventaja frente a los métodos usuales en que los detalles de un preparado pueden ser reconocidos no solo fieles al objetivo sino también con todos los elementos interiores de la célula. Los inconvenientes que ofrece el preparado teñido, causados inevitablemente por fijación y coloración, son eliminados.

El solo proceso de fijación provoca ya en las partes plasmáticas de una célula, considerables alteraciones, pero también en el espacio nuclear se forman cuadros que no corresponden en todas sus partes a la materia viva. La instantánea solidificación cel objeto teñido engañan por lo menos respecto al tamaño y a la forma de varios detalles morfológicos.

Solo los objetos delgados dan una imagen favorable; capas gruesas, por ejemplo, varias capas celulares, no se prestan para ser observadas.

El material puede ser observado, diluído o no diluído. Los preparados obtenidos por desmenuzamiento o aplastamiento se prestan bien para representación vital, si el objeto es preparado cuidadosamente. Para observaciones de corta duración, el mate-

(*) Trabajo presentado al III Congreso Colombiano de Obstetricia y Ginecología. Ibagué, 1959. 


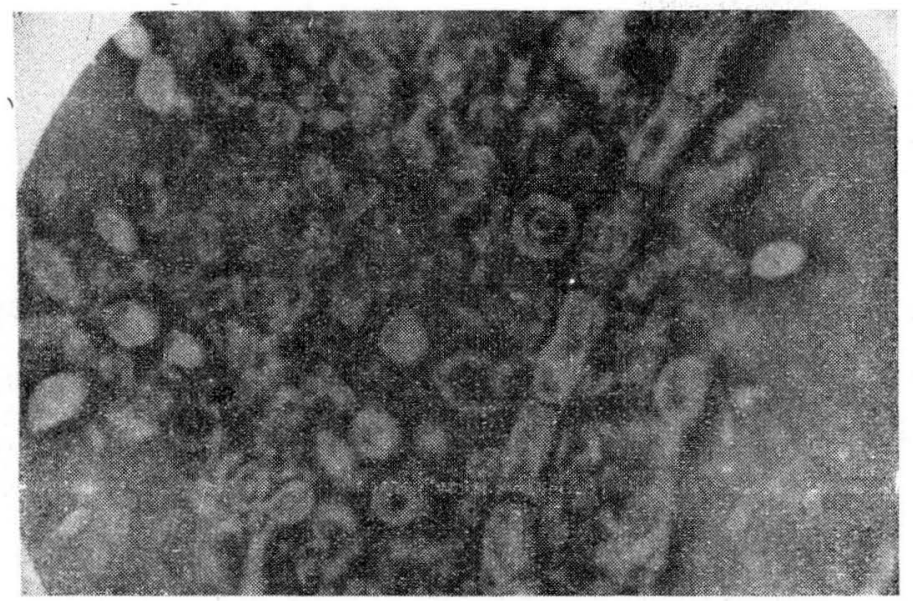

Figura número 1.-Micelios y esporos de hongos - Monilias.

rial provisto de un cubre-objeto es perfectamente suficiente. Sin embargo, hay que prestar siempre atención a que se empleen porta-objetos y cubre-objetos delgados, para obtener condiciones óptimas. Es conveniente colocar alrededor del preparado un borde de parafina o vaselina, lo cual protege el preparado contra la rápida desecación, dando un margen de tiempo mayor para su estudio.

\section{EMPLEO DEL METODO}

En ginecología el procedimiento fue propuesto por primera vez para el diagnóstico de tricomonas vaginales, de grados de limpieza de la vagina y para la observación de células tumorales.

De gran importancia es el contraste de fases para el espermograma, pues se aprecia claramente la motilidad y penetrabilidad del espermatozoide en el moco cervical, así como la morfología espermática.

El trasudado vaginal constituye uno de los objetos más favorables para la microscopia vital. La preparación diluída admite un examen ideal, rico en contrastes, sin artificio alguno. Es, por lo tanto, el procedimiento más sencillo para obtener rápidamente un conocimiento sintético de la composición bacteriana. parasitaria y citológica del contenido vaginal. Los agentes patógenos más esenciales que viven en la luz vaginal, pueden ser determinados fácilmente y la apreciación de grados de limpieza vaginal no presenta dificultades. 


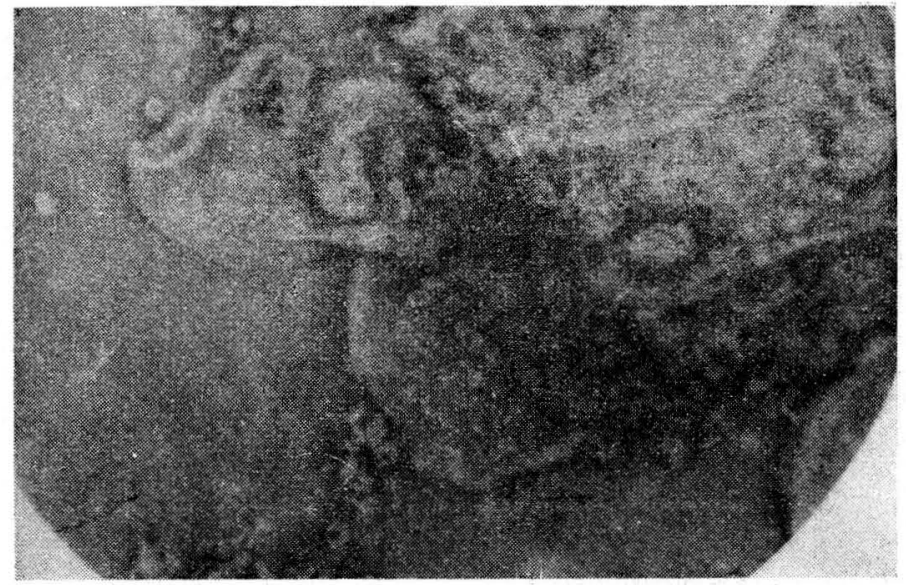

Figura número 2.-Esporos cie hongos - Monilias - Células superficiales de la vagina.

El bacilo de Doderlein y sus formas involutivas se representan como bastoncitos largos típicos o como tipo pequeño degenelativo reunido en aglomeraciones. Sus variedades de forma desde filamentos largos haste formas cocoides, son reconocidas fácilmente. El solo examen del preparado basta para orientarse sobre la cantidad de flora mixta, se reconocen estreptococos y estafilococos, coli, sarcinas, comas variables, etc. Los espiroquetos y espirilos son de fácil diagnóstico. Afecciones micóticas pueden ser observadas con particular ventaja en el frotis vivo.

Con el procedimiento de contrastes de fases se logra comyrobar al lado de las formas flageladas de tricomona vaginal, las formas ameboides y císticas; en el preparado fijado y teñido, su comprobación no es posible.

\section{DIAGNOSTICO CITOHORMONAL}

Las células representadas en el preparado vital ofrecen ya en condiciones normales muchos detalles que en la imagen teñida se pierden en parte. La célula superficial se presenta en la imagen celular vital como de forma poligonal con núcleo pequeño denso, produciendo un contraste intensamente oscuro. Todo proceso de diferenciación en la célula epitelial está acompañado de un aumento de los gránulos del plasma. Este proceso es activado por la influencia de la hormona folicular y en el curso de la primera fase cíclica, estos cuerpos aislados aparecen en número creciente en el plasma. A menudo aparecen formaciones granu- 


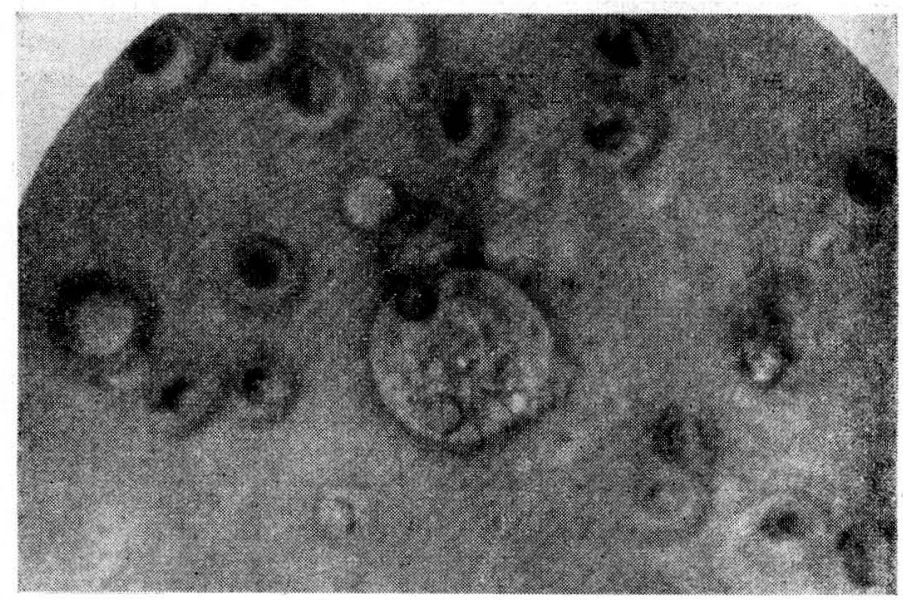

Figura número 3.-Células carcinomatosas y glóbulos rojos.

lares muy grandes, características del efecto estrogénico. Es típico un halo libre de gránulos alrededor del núcleo, destacándose éste con tanta claridad, que parece encontrarse en una cavidad. El borde dentado se hace nítido, siendo signo seguro de proceso intenso de diferenciación.

El efecto progestacional puede ser observado fácilmente, no solo por rasgos característicos ya conocidos, sino por una completa desaparición de los gránulos celulares. Las células de la capa intermedia, que como sabemos predominan progresivament€ en esta fase, están caracterizadas por un núcleo claro de tamaño apreciable, que presenta estructuras internas delicadas y generalmente un contorno típico que se extiende transversalmente. Los procesos de arrugamiento parecen condicionados por una disolución de las estructuras plasmáticas. El hialoplasma presenta un contraste turbio difuso y las células pueden unirse hasta formar grupos completamente apelotonados sin que aún puedan reconocerse partes del interior. A base de estos rasgos resulta parcialmente fácil reconocer la fase luteínica.

Las células de las capas profundas son redondas, globulares. $u$ ovuladas. $\mathrm{Su}$ espesor hace aparecer, a veces, un halo de origen ćptico alrededor de la célula. Su contraste citoplasmático puede ser distinguido claramente de las capas epiteliales medias y superiores y se presentan como sombra homogénea oscura. Las células para-basales no poseen los gránulos plasmáticos. 
El espacio nuclear no da generalmente un contraste. Los núcleos son, pues, claros, de forma irregular y un nucleolo raras veces visible. Esto se aplica a las células del epitelio, difícilmente estructurado en la menopausia y la amenorrea trófica. En los tipos proliferentes de la capa para-basal que se desprenden del cuello, siempre se pueden reconocer pequeños núcleos y más a menudo se encuentran vacuolas en el protoplasma.

Las células germinativas basales apenas aparecen en condiciones normales. Son cúbicas o redondas y poseen un núcleo globular muy claro que muchas veces permite observar cromomeros. Las células del endometrio desprendidas por descamación antes de la menstruación, aparecen aisladas o en conglomerados compactos; son generalmente tipos pequeños, regulares, con un núcleo claro que presenta con nitidez un nucleolo. Su citoplas-ma aún es visible, apenas como borde delgado.

Las partes acompañantes del frotis (leucocitos, linfocitos, células plasmáticas y macrófagos), no solo están representadas morfológicamente hasta las más delicadas estructuras aisladas, sino que también es posible seguir a estas células de cerca en sus procesos biológicos. En condiciones biológicas no perturbadas los leucocitos aparecen contraídos y carecen de vida. En la imagen celular anormal, adoptan propiedades emeboides, presentan vivos movimientos moleculares en el borde plasmático y con tendencia a la disolución. Vacuolas claras dentro de estas células que contengan bacterias fogocitadas vivamente movibles permiten suponer la presencia de condiciones alteradas.

Los eritrocitos están representados como elementos oscuros, en forma de escudillas y a veces presentan cierta plasticidad y aparecen en los diferentes periodos de su destrucción, hasta las formas anulares.

En general el procedimiento de contraste de fases hace posible la diferenciación irrecusable de todas las partes celulares en forma más clara y precisa que en los métodos conocidos.

\section{DIAGNOSTICO DE CANCER}

El valor del procedimiento de contraste de fases para la citopatología ha sido reconocido cada vez más en los últimos años. El método, hoy día, figura entre los medios auxiliares más indispensables en la investigación del carcinoma.

La imagen celular fásico-óptica resulta al principio poco familiar al investigador y presenta una abundancia de detalles, especialmente en células atípicas, que pueden ser registradas solo 


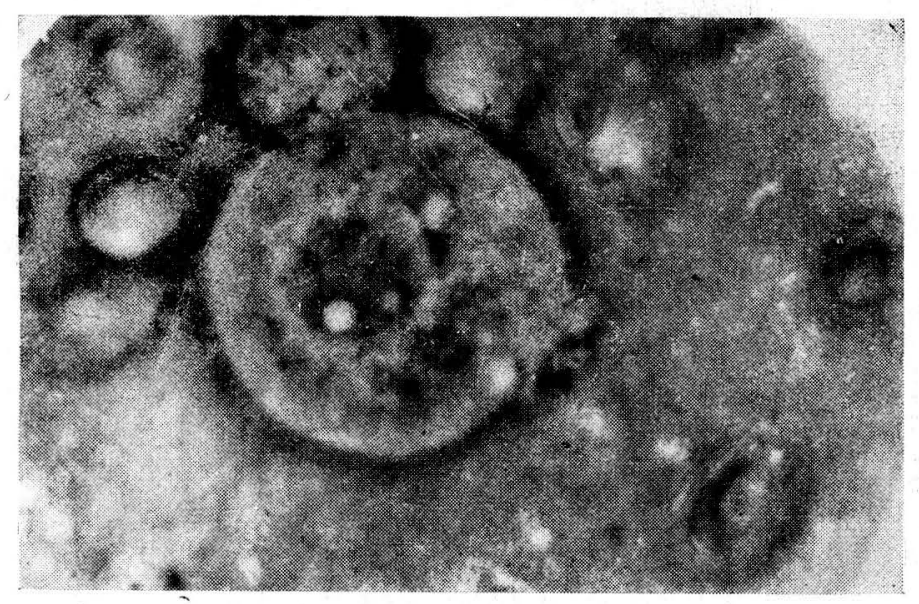

Figura número 4.-Células carcinomatosas, glóbulos rojos.

(iespués de raberse adquirido mucha práctica. Además de los rasYos típicos suficientemente conocidos, que son considerados como relativamente característicos de una degeneración neoplásica de ia célula, el procedimiento ofrece la posibilidad de incluir, en proporciones mucho más amplias, las alteraciones celulares, no solo cariológicas sino plasmáticas.

A continuación expondremos los rasgos característicos que una célula degenerada permite reconocer en la imagen de contraste. Las correlaciones entre núcleo y plasma, perturbadas en ios procesos de degeneración cancerosa, pueden ser visibles claramente en el contraste de fases.

En primer lugar se encuentran anomalías cariológicas de la célula tumoral (anisonucleosis, polimorfismo, perturbación de reZación núcleo-plasma, etc.). Estos rasgos clásicos en la imagen teñida están representados fásico-ópticamente en forma tan impresionante porque la sustancia nuclear no sufre fenómenos de contracción, permaneciendo perfectamente conservadas las alteraciones de la forma. Las pequeñas formas celulares y nucleares son consideradas como las portadoras esenciales del crecimiento maligno, mientras que los tipos nucleares macizos pertenecen a las células de carácter subletal y no presentan potencias de proliferación.

La sustancia fundamental de los núcleos, es sorprendentemente clara. El contorno del núcleo está a menudo engrosado y deja ver un filamento de partes de cromatina, pegados a la pazed interior, pareciendo un collar de perlas. En casos aislados, la 


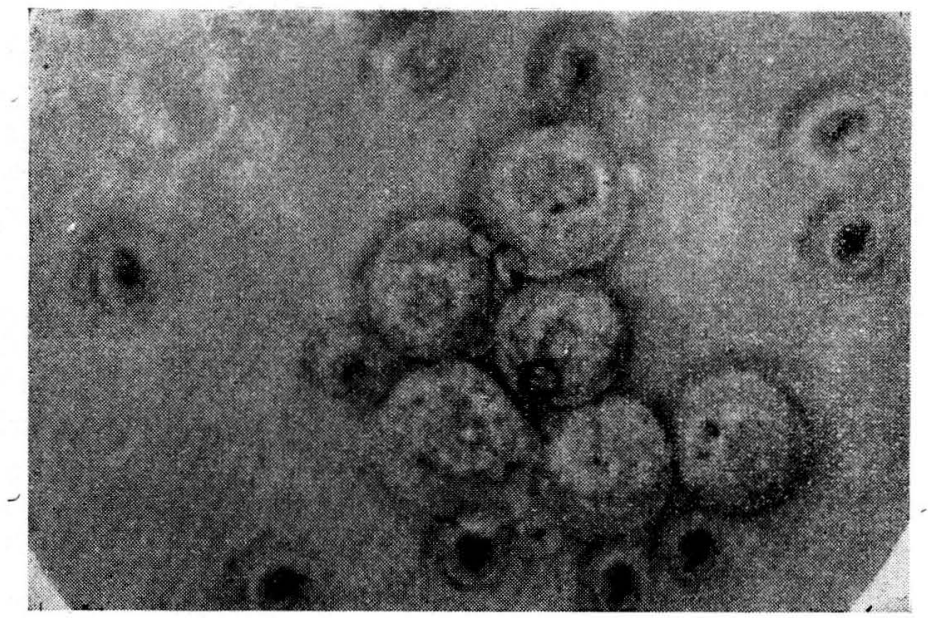

Figura número 5.-Grupo de células carcinomatosas, glóbulos rojos.

formación nuclear parece acercarse al estado de picnosis, uno o varios corpúsculos se destacan nítidamente. Los nucleolos pueden adoptar un tamaño poco com'in y a menudo dejan reconocer vacuolas en su interior.

Los procesos de fusión celular tienen gran importancia; apavecen formas polinucleares que a veces contienen inmensos núcleos conglomerados. A veces se comprueba la encajadura de unas células en otras (nacimiento celular). También en raras excepciones se reconocen atípicos procesos de fraccionamiento (congiomeración, fragmentación, aglutinación), así como perturbaciones coriocinéticas.

Pueden observarse dentalladuras de la pared nuelear, debido a las cuales se forman figuras nucleares en semiluna. En el punto conde falta la membrana nuclear sale y entra en el plasma como vacuola, una sustancia clara.

Los fenómenos de fogocitosis, que se pueden reconocer por los numerosos cuerpos incluídos y que han conducido a muchas suposiciones generalmente refutadas, son para el diagnóstico de una importancia secundaria. En cambio, la propiedad de las células, de recoger leucocitos, células plasmáticas, eritrocitos y detrito celular, corresponde a una alteración que se produce en mayor grado, existiendo una degeneración cataplástica de la célula.

Se pueden reconocer cavidades plasmáticas, parecidas a "ojos de pájaro", descritos por Leyden Plimer, como también espacios vacuolares en el plasma celular que desplazan al núcleo, formando céluJas parecidas a un anillo de sello. 
La disociación de la sustancia plasmática, consecuencia de la incapacidad de formar una estructura celular, conduce a la disolución en elementos de diverso tamaño. En el material del frotis de superficie estos cuerpos pueden ser encontrados en abundancia en forma de mitocondrias o como porciones globulosas que aparecen en masa en el campo visual, con movimientos propios que dan en conjunto una característica especial.

Después de la total disolución del citoplasma se produce la formación de núcleos libres desnudos que aparecen aislados o en grupos. A este rasgo característico ha atribuído gran significadio patognomónico, y Foster ha visto en la aparición de estos núcleos desnudos el primer comienzo del carcinoma.

Por lo expuesto hasta el presente, el procedimiento de contraste de fases ha tomado auge, principalmente entre los investigadores europeos que ven en el método una simplificación del trabajo; grandes ventajas sobre los métodos vitales y de coloración usuales.

\section{VENTAJAS DEL METODO}

1. La ausencia de fijación evita las alteraciones estructurales.

2. El frontis puede ser examinado inmediatamente y reexaminarse en caso de ser insuficiente.

3. La profundidad del campo está ampliada.

4. Las características anormales del citoplasma son más aparentes y reconocibles que en los frotis fijados.

5. El método es fácil y poco costoso.

\section{DESVENTAJAS}

1. Las preparaciones poco se conservan, exigiendo el examen en las 24 horas siguientes.

2. Dificultad de transportar los preparados.

3. La ausencia de caracteristicas relacionadas con las afiniciades tintoriales. 